\title{
g4c2c: A Model for Citizen Engagement at Arms' Length from Government
}

\author{
${ }^{*}$ Axel Bruns, ${ }^{* *}$ Adam Swift \\ ${ }^{*} A R C$ Centre of Excellence for Creative Industries and Innovation, Queensland University of Technology, Brisbane, \\ Australia.a.bruns@qut.edu.au-http://snurb.info/ \\ ** Creative Industries Faculty, Queensland University of Technology. a.swift@qut.edu.au
}

\begin{abstract}
The recognition that Web 2.0 applications and social media sites will strengthen and improve interaction between governments and citizens has resulted in a global push into new e-democracy or Government 2.0 spaces. These typically follow government-to-citizen (g2c) or citizen-to-citizen (c2c) models but both these approaches are problematic: $g 2 c$ is often concerned more with service delivery to citizens as clients, or exists to make a show of 'listening to the public' rather than to genuinely source citizen ideas for government policy, while c2c often takes place without direct government participation and therefore cannot ensure that the outcomes of citizen deliberations are accepted into the government policy-making process. Building on recent examples of Australian Government 2.0 initiatives, we suggest a new approach based on government support for citizen-to-citizen engagement, or g4c2c, as a workable compromise, and suggest that public service broadcasters should play a key role in facilitating this model of citizen engagement.
\end{abstract}

Keywords: government 2.0, web 2.0, e-democracy, g4c2c, civic commons

R ecognition of both the need for and the potential afforded by Web 2.0 applications has resulted in a global push by both governments and citizens into new e-democracy or Government 2.0 spaces. The Council of Europe's Ad Hoc Committee on e-Democracy (CAHDE) - a leading space for discussion and debate of the issues that surround Government 2.0 - suggests, for example, that while governments are faced with declining participation in political life and low public appreciation of democratic institutions, citizens too feel a lack of inclusion and empowerment with little impact beyond the election cycle, leading to a sense of decreased legitimacy of parliamentary decisions within electorates, and a growing mistrust in democratic institutions (CAHDE, 2008, 2009). Coleman and Blumler have summarised this position, observing that, "in most contemporary democracies ... the representative relationship is in chronic disrepair. There is a pervasive sense that politicians and the people they represent inhabit different worlds, speak mutually incomprehensible languages and fail to respect one another" (2009, p.69).

Projects aiming to foster citizen engagement through e-participation may be able to help arrest this decline. While such Government 2.0-style initiatives are gaining momentum in Australia, too, it is difficult to accurately gauge the extent to which the issues CAHDE identifies are mirrored in Australia. Having evolved from European traditions, Australian political and parliamentary institutions continue to be influenced by both emerging problems and potential solutions that develop in similar democracies and observations of European Government 2.0 initiatives are clearly useful to discussions of Government 2.0 in Australia. Nevertheless, from a purely functionalist point of view, Australian voters need not be encouraged to participate: compulsory voting in Australia (and compulsory electoral enrolment for all Australian citizens aged 18 years and over) has delivered voter turnout of around $95 \%$ at every federal election since 1924 (AEC, 2009a). In recent years there has also been a small reversal of informal votes, from national highs of $4.71 \%$ in 2004 to $3.55 \%$ in the 2007 election (AEC, 2009b). This suggests to some extent an informed and involved - if somewhat less than enthusiastic - electorate: Australians have no (legal) choice but to at least engage in the most fundamental activity of democracy. More so than in 
countries with voluntary voting, the challenge in Australia is thus to enhance the quality of citizens' participation in the political process rather than achieve sufficient critical mass in the first place: that is, to explore the extent to which the Internet can change the balance of communicative and political power as citizens and non-governmental entities continue to question, comment upon, challenge and influence their governments.

Nevertheless, the integration of ICTs into political culture is seen as a serious challenge for Australian governments at federal, state, and local level, many of which have begun to explore government-to-citizen (g2c) service and consultation models. Citizens in Australia and elsewhere have also taken the initiative in discussing public affairs on social media sites and blogs on a citizen-to-citizen (c2c) basis. In doing so, they have established a number of online communities that are filled with relevant expert, specialist, and often local knowledge that may exceed that of their elected representatives and of industry lobby groups. Elected federal, state, and local politicians are usually absent from such communities but at the same time, the communities themselves cannot also claim to be representative of wider Australian popular opinion, as participation in Web 2.0 is far from uniform across the Australian populace; the discussions in relevant online communities often remain discussions of the digital elite.

Thus, while the technological infrastructure is available, systemic change is needed in order to fully realise how the underlying dynamics of participatory social media cultures can be effectively harnessed to build, maintain and promote more quality participation and engagement between government and citizens (g2c) as well as between citizens themselves (c2c). Leadbeater has proposed that the social media culture of participation and collaboration provides a way of reforming public services that can serve as an alternative to the top-down imposition of service targets and the creation of quasi-markets by "mobilising citizens as player-developers in creating public goods" (2008, p.153). This would redefine the role of the citizen as what Bruns (2008b) terms 'produsers' of government services. Our public institutions may need to be shown, for example, that increasing the involvement of citizens in policy-making might result not only in better outcomes at a reduced cost but might actually provide innovative solutions and policies that are responsive and reflective of the greater diversity that constitutes the broader community; similarly, a broader group of Australians may need to come to an understanding of online political communities as a tool for broad-based popular action rather than as a mere talkfest for political junkies.

\section{Introduction}

In addressing questions of citizen engagement with social media from the perspective of public policy, Stephen Coleman has observed that if "the framing of 20th-century politics by broadcast media led to a sense that democracy amounted to the public watching and listening to the political elite thinking aloud on its behalf," the rise of interactive online and networked media "opens up unprecedented opportunities for more inclusive public engagement in the deliberation of policy issues" (2005, p.209). Web 2.0 applications can make the operation of government a more consultative and participatory process that utilises the extensive knowledge, views, and resources of citizens. Web 2.0 applications can also provide understandable and accessible information on a range of democratic processes, together with a greater transparency of political systems and dependencies within democratic institutions. Web 2.0 applications can also enable citizens to engage with political discourse from a secure and familiar place, such as their own home or workplace: spaces which, Coleman and Blumler (2009, p.83) write are "typical spaces of political opinion formation and exchange." And Web 2.0 applications can increase citizen access to customised and useful information resources via improved services and quality of data.

In 2009 the Australian federal government's Government 2.0 Task Force (Department of Finance and Deregulation, 2009) explored the scope for social media technologies and cultures to improve government service delivery and citizen engagement, combined with the enhanced possibilities to manage and use government data, provide information and facilitate communication 
in digital modes. The task force's report eloquently outlined the opportunities available in this space:

By embracing Government 2.0 we can:

- Make our democracy more participatory and informed.

- Improve the quality and responsiveness of services in areas like education, health and environmental management and at the same time deliver these services with greater agility and efficiency.

- Cultivate and harness the enthusiasm of citizens, letting them more fully contribute to their wellbeing and that of their community.

- Unlock the immense economic and social value of information and other content held by governments to serve as a precompetitive platform for innovation.

- Revitalise our public sector and make government policies and services more responsive to people's needs and concerns by:

- Providing government with the tools for a much greater level of community engagement.

- Allowing the users of government services much greater participation in their design and continual improvement.

- Involving communities of interest and practice outside the public sector - which offer unique access to expertise, local knowledge and perspectives - in policy making and delivery.

- More successfully attracting and retaining bright, enthusiastic citizens to the public service by making their work less hierarchical, more collaborative and more intrinsically rewarding.

Government 2.0 will be central to delivering on critical national objectives including delivering on our National Innovation Agenda - including the aspiration for a more innovative public sector. It will be central to addressing the desire of the Advisory Group on the Reform of Australian Government Administration to establish in Australia the world's best public service which puts citizens at the centre of everything it does. It will be an important component of the Department of Human Services service delivery reform agenda. It can improve social inclusion. And it will enable us to make the most of our huge broadband investment making Australia a more connected democracy. (Government 2.0 Taskforce, 2009, pp.xi-xii)

Existing 'Government 2.0' initiatives in Australia have variously employed g2c top-down approaches, such as the exploration of blogging by government agencies, consisted of c2c bottomup initiatives by non-government organisations (like Open Australia's Project Democracy), or emerged from the personal engagement of politicians and other political actors in social media environments (Bruns \& Wilson, 2010). Most recently, the Government 2.0 Task Force itself has been instrumental in driving forward the digital agenda, for example through its sponsorship of the Mashup Australia contest for innovative online applications that build on government data made available through the data.australia.gov.au portal ${ }^{1}$ and its funding of a range of research and development activities. ${ }^{2}$ This work is also complemented by related initiatives by several Australian state and territory governments.

What must be acknowledged within this framework is that the philosophies and ideals that have come to be seen as being typical for Web 2.0 applications and social media initiatives do not belong exclusively to the online realm. Whilst the possibilities for participation and engagement have certainly been strengthened by Web 2.0 applications, the range of opportunities that are afforded to both governments and citizens - such as community consultation and crowdsourcing,

\footnotetext{
${ }^{1}$ http://mashupaustralia.org/

${ }^{2}$ http://gov2.net.au/projects/
} 
resource sharing, networking, issue facilitation, collaboration, collective openness and recommendation services - spill back into the offline meeting halls and public spaces in new or reinvigorated ways.

Drawing on our observation of the Australia 2020 Summit (which brought together some 1,000 leading Australians from politics, industry, and public life to discuss future visions for the nation) and of the limited role that the national publicly funded broadcaster played in its coverage, this paper proposes a new framework for Web 2.0 enabled government and citizen interaction. Discussing what could have been done in the space afforded by the 2020 Summit, we outline an approach that encourages stronger participation in policy-making and implementation by moving beyond merely top-down or bottom-up processes towards a form of ' $\mathrm{g} 4 \mathrm{c} 2 \mathrm{c}$ ' citizen and government interaction that is supported through and distributed across a variety of non-governmental thirdparty spaces.

\section{From g2c and $c 2 c$ towards $g 4 c 2 c$}

Online as well as offline, the perennial problem with any government-sponsored, g2c citizen engagement and consultation initiative is that it may be seen by its detractors (such as opposition parties and other critical groups) as a futile exercise in 'ticking the boxes', while even genuinely engaged participants may re-emerge from the participative process with a less than enthusiastic frame of mind if there are no clear pathways from the outcomes of g2c consultation to actual implication through government action. Part of this may be explained by the observation that there is by now an almost habitual public suspicion that governments of any colour engage in political spin almost as much as in actions of political substance; even genuinely substantial g2c initiatives will find it difficult to overcome this negative mindset.

In comparison to the fragmented outcomes of g2c initiatives, participatory social media projects established by activist and non-government organisations have often been able to attract comparatively more public participation. Projects such as the UK-based They Work For You or the Australian Project Democracy draw on publicly available information about parliamentary processes to allow citizens to track the activities of their representatives and directly discuss and respond to their actions. And campaigning organisations such as MoveOn in the USA and GetUp! in Australia have effectively used social media technologies to coordinate citizen action in support of specific initiatives and aims (Bruns \& Wilson, 2010). But while c2c engagement and deliberation initiatives tend to suffer less from such inherent suspicion and to engender more open and constructive debate (unless operated by obviously politically biased non-government organisations), they must instead counter a public perception that even in spite of sometimes significant enthusiasm and activity by participants they will find it difficult to develop the political traction required to convert their ideas, knowledge, and innovation into binding and actionable policy outcomes adopted by the government of the day. Lacking direct and substantial government involvement, and in fact at times setting out with the explicit aim of developing an alternative to what is perceived as bad policy, c2c initiatives often operate at too far a remove from the realm of political decision-making to be able to connect with the policy development process in a way that generates any measurable consequences.

Another way of describing this same dilemma is that g2c is often seen as overly focussed on quantity (where outcomes may be measured in the amount of citizen submissions received, the number of 'clients' served, or the impact on poll results for governments), with little attention paid to the experiential quality of the process for its citizen participants. In principle, g2c initiatives are attractive for citizens as they promise a direct line into the policy-making process (calls for public submissions to government enquiries regularly generate a large volume of contributions that reflects the full breadth of society, for example), but in practice, they often have considerably less impact on those policy-making processes than negotiations within the political establishment itself (of the hundreds or thousands of submissions made to such enquiries, the handful which are taken seriously are usually those from well-known academic, industry, and lobby groups). What results 
from g2c processes operating in this way can be the cynics' view that citizen participation is invited only to make up the numbers and give democratic legitimisation to already preordained policy decisions.

Conversely, c2c processes may well cater more strongly for quality participation, but frequently lack measurable impact on policy processes (especially where they are orchestrated without government involvement). Here, the cynics may regard c2c as generating endless discussion and debate which feels engaged, but ultimately achieves very little: where g2c provides a fig leaf enabling governments to document how responsive they are to their constituency, without much real impact on government policy, c2c can generate open and meaningful debate, with even less real impact on government activities. Additionally, their lack of involvement in a c2c initiative provides a clear excuse for governments to ignore its outcomes and/or to dismiss it as unrepresentative of wider community views. In turn, then, this withholding of official recognition for the outcomes of their discussions may serve to further frustrate citizens engaging in c2c processes, and to undermine the perceived legitimacy of the processes themselves.

What would be desirable, then, is an approach that combines the advantages of both models into a more fully integrated whole: an approach that marries together the quantitative advantages of g2c and the qualitative strengths of $\mathrm{c} 2 \mathrm{c}$ by harnessing the more unencumbered community spirit of government-independent $\mathrm{c} 2 \mathrm{c}$ models but maintaining a strong commitment from government to participate in the citizen engagement process and to seriously consider its outcomes as potential policy initiatives. This approach requires a leap of faith from both sides, then: from the NGOs that operate the c2c platforms, who must find ways to accommodate more direct participation by government representatives and therefore share their ownership with government partners (in comparison with $\mathrm{c} 2 \mathrm{c}$ models), and from participating governments and their representatives, who must accept the less than total control over the citizen engagement platform that they now have, as well as cope with the increased unpredictability of the outcomes of the process (in comparison with g2c models).

This is a hybrid model which is neither simply g2c nor c2c, but instead relies on government support for and participation in citizen-to-citizen engagement activities which remain otherwise at arm's length from direct government control and supervision; thus, it may be described as $g 4 c 2 c$. In this model government organisations would provide their support to and partner with third-party, non-government entities, whose role and responsibility it is to facilitate the day-to-day citizen engagement processes.

Although perhaps more by accident than by design, the Australian government's Government 2.0 Task Force initiative - and especially its public presence online - may itself be described as an early attempt at exploring the g4c2c model, in fact: contrary to the federal Department of Broadband, Communications, and the Digital Economy's controversial Digital Economy blog trial which preceded it (and influenced no doubt by the trial's overall lack of success - Bruns \& Wilson, 2010; Griffiths, 2009), it is notable that the Task Force set up its online space (centred around its Wordpress-based group blog) at gov2.net.au, outside of the .gov.au domain and thus in a more neutral, arm's-length environment unaffected by federal directives for the management of official Websites. In doing so, even while clearly a government body, the Task Force was able to present itself as a quasi-NGO, and this relative independence afforded the Task Force a greater freedom to facilitate a more genuine and open citizen-to-citizen engagement around the issues it pursues than would have been possible on a government Website. It qualifies as a g4c2c initiative from that perspective; however, whether the outcomes of the Task Force's research, consultation, and development activities are adopted and adapted into official government policy remains to be seen. (The policy recommendations in its December 2009 report are encouraging, however.)

At the same time, it must be noted that due to its topical focus, and in spite of the implications it may have for future government activities overall, the Government 2.0 Task Force necessarily remains of interest only to a comparatively small minority of the Australian population, and that its relatively ad hoc, off-the-shelf Web presence would not be suitable for more broadly-based citizen engagement initiatives. At this higher level, g4c2c initiatives require government partnerships with 
strong, competent, and widely respected third parties which can successfully claim to be organisationally independent from the government itself. In many Western democracies - with the notable exception of the United States - it is possible that public service broadcasters may step into this role (especially where they have already made a start on shifting their focus from the conventional broadcast, mass-media model to a multicast, new media approach - Flew, Cunningham, Bruns \& Wilson, 2008): for the most part, such public broadcasters are seen as - and committed by their charters or statutes to be - independent, critical media organisations, mostly free of political bias or interference. This is true, for example, for the national publically funded broadcaster of Australia, the Australian Broadcasting Corporation (ABC).

\section{3. g4c2c Opportunities at the Australia 2020 Summit}

In this light, we revisit the Australia 2020 Summit, which was held 19-20 April 2008 at Parliament House in Canberra, the Australian federal capital, and covered extensively by the $A B C$ on its then new digital television channel ABC2. Announced by the newly elected Labor Party Prime Minister Kevin Rudd, the Australia 2020 Summit aimed to "help shape a long term strategy for the nation's future", and was facilitated by 1,000 invited politicians, academics, business and industry representatives, community leaders, and other public identities, divided into 10 working groups of 100 discussing 10 'critical areas'3 (Department of The Prime Minister and Cabinet, 2008a). The organising committee outlined the following objectives for the summit:

- To harness the best ideas across the nation.

- To apply those ideas to the 10 core challenges that the Government has identified for Australia - to secure our long-term future through to 2020.

- To provide a forum for free and open public debate in which there are no predetermined right or wrong answers.

- For each of the Summit's 10 areas to produce following the Summit options for consideration by government.

- For the Government to produce a public response to these options with a view to shaping the nation's long-term direction from 2009 and beyond

(Department of The Prime Minister and Cabinet, 2008a).

Many Australians saw the Summit as an innovative and grand idea, and a bold move from a newly elected government determined to sell its ethos as a government for all Australians; alternatively, however, others regarded it as a mere public relations exercise, designed to generate a positive perception of the government as open and responsive but to achieve little in the way of substantial outcomes.

Before the Summit, Australians were invited to make submissions and to participate in online fora where they could share ideas and start discussions, often in participation with Summit delegates and members of the steering committee. While criticism was directed towards these fora, with one commentator suggesting that "the site was difficult to navigate, late in starting, accessed by few and there were controls over the interaction" (Harvey, 2009, n.p.), the volume of

\footnotetext{
${ }^{3}$ The 10 critical areas were identified as:

1. The productivity agenda - education, skills, training, science and innovation.

2. The future of the Australian economy.

Population, sustainability, climate change and water.

Future directions for rural industries and rural communities.

5. A long-term national health strategy — including the challenges of preventative health, workforce planning and the ageing population.

6. Strengthening communities, supporting families and social inclusion.

7. Options for the future of Aboriginal and Torres Strait Islanders.

8. Towards a creative Australia: the future of the arts, film and design.

9. The future of Australian governance: renewed democracy, a more open government (including the role of the media), the structure of the Federation and the rights and responsibilities of citizens.

10. Australia's future security and prosperity in a rapidly changing region and world.
} 
submissions received and discussion generated prior to the Summit was perhaps indicative of the public anticipation that surrounded the event. Similarly, it seems that for the most part, the optimism and mutual respect of participants at the Summit ensured that good, genuine and constructive participation and collaboration occurred amongst the delegates. However, just days after the conclusion of the event the online fora were shut down, and the ideas that emerged from the Summit where quickly collected, collated, sanitised, organised, edited, and published by staff within the Department of the Prime Minister and Cabinet under the unimaginative title Australia 2020 Summit - Final Report (Department of the Prime Minister, 2008b). Far from kick-starting a continuing conversation between the government and the public on the 'big issues' facing the nation, the publication of the report on 31 May 2008 seemed to signify a final closing of the discussion. This appeared to vindicate negative perceptions of g2c as mere feel-good spin.

Held less than six months after the election of a new federal government, the 2020 Summit occurred before the articulation of the government's Web 2.0 initiatives and the incorporation of the Government 2.0 Task Force, and before similar substantive changes within the $A B C$ which have seen the organisation embrace Web 2.0 to an unprecedented extent (Australian Broadcasting Corporation, 2009). Thus, while many of the participatory elements which are today associated with Web 2.0 were also observable in an offline setting at the 2020 Summit, at least as aspirational principles, they failed to be translated in full to the online presence of the Summit itself, or to its media coverage. Much of the journalistic coverage of the event concerned itself more with irrelevant details of process - such as whether butcher's paper was used in deliberations, or that the Prime Minister sat on the floor in one oversubscribed group discussion - than with the substance of the debates (Bruns, 2008a; Crabb, 2008). Perhaps most problematic was the premature and unexpected termination of follow-on discussion after the event - an unnecessary intervention by the government which seemed motivated mainly by an internal departmental need to meet the performance target of producing a final report, but in effect led to the dissipation of a great deal of enthusiasm as it denied participants an outlet for their energies.

Overall, then, while - like other Australian government engagement initiatives, perhaps - the Summit was well-intentioned in its attempt to call on the nation's best and brightest for the benefit of their knowledge and experience, and to connect this with ideas and contributions sourced from the broader Australian community through the Summit Website, the initiative failed to create a measurable, lasting impact because it was too focussed on the event itself, and lacked any strategy for continuing the discussion and maintaining the momentum beyond the two days of the Summit itself. The quantitative, events and outcomes-driven mindset of standard governmentdriven g2c activity failed to be suitably complemented and tempered by a qualitative, participation and engagement-focussed attitude as it tends to exists in community-based c2c initiatives; indeed, there was no sign that government representatives even recognised the available community momentum, nor that they had any strategies for harnessing it.

Far from being a resounding success, then, the 2020 Summit nonetheless points to the possibilities for citizen engagement and deliberation at a large scale, and we may learn some useful lessons from the experience. Chiefly, the government itself may not necessarily have been the best-placed driver of the Summit, and if we understand the Summit as a kind of 'proto-g4c2c' event it is possible to sketch out a number of suggestions for how a repeat event could be staged differently and better.

Unsurprisingly, both before and after the Summit many commentators, particularly within the blogosphere, viewed the Australia 2020 Summit as an early foray into a 'whole-of-government' approach to Government 2.0 principles and ideas - albeit without Internet technologies and, regretfully, without the ongoing discussion such technologies enable. There is little doubt amongst such commentary that greater employment of technology should have been harnessed during and beyond the conference.

"If the 2020 Summit were held today many things would be different and there would be much less tolerance of a lack of online engagement. Before during and after the event Twitter, live 
blogging and other tools that take events beyond the boundaries of walls, would play a much greater role. Collaboration online for submissions and brainstorming ideas, capturing the conversation in different places, sharing and discussion by a much wider audience would create a stronger interaction between participants and populous [sic], making the whole thing more democratic. A kind of uncontrolled, spontaneous online discussion of it all would occur, which is how it should be" (Harvey, 2009, n.p.)

This is also an argument for drawing not only on the officially sanctioned fora for online discussion and input into the Summit but also on public discussions on relevant topics as they may be carried out across a wider range of social media spaces - including the blogosphere, Facebook, and Twitter. However, it must be acknowledged that the government at the time showed little or no interest in maintaining an ongoing 'uncontrolled' discussion with the electorate about the ideas generated via the Summit.

[In providing this response], "the Government ... may accept some options and reject others - but will provide its reasons for embracing its course of action for the future

The Government has no interest in a talkfest. The Government's interest is in harnessing and harvesting ideas from the community that are capable of being shaped into concrete policy actions" (Department of The Prime Minister, 2008a)

In this regard the government failed to recognise that the mechanisms made available by Web 2.0 applications and social media sites mean that public consultation and collaboration particularly that which takes place around such large-scale ideas - can no longer be controlled or maintained by the government (Bruns \& Bahnisch, 2009, Bruns, 2009). People will continue to discuss the ideas raised during the Australia 2020 Summit that remain important to them, and will likewise discuss within their own communities whether and how governments have or have not taken their concerns into account. And they will continue to use these mechanisms to question the governments of the day on how well they implement recommendations or policy ideas resulting from consultations to which they rightfully feel they have made an interested contribution.

By distancing themselves from and curtailing broader and ongoing community consultation and citizen participation, government initiatives such as the Australia 2020 Summit often do little more than present as 'big targets' for the community, often resulting in large numbers of individual submissions (both on and off-topic), while providing little scope for feedback and offering even less in terms of community development. As noted by Bruns and Wilson in the context of the Australian federal Department of Broadband, Communication and the Digital Economy's (DBCDE) Digital Economy consultation blog, while participation and engagement tools that are developed in a topdown' fashion by government agencies may seem to provide a more direct line of communication to relevant government officials, they are also more likely to be swamped by users who wish simply to register their dissent rather than engage in discussion (Bruns \& Wilson, 2010). Rarely are g2c spaces given the time that is required for real, sustainable and self-managing community structures to develop. Perhaps a sense of foresight prompted officials in the Department of Prime Minister and Cabinet to close the online discussion fora within days of the Summit closing - but by doing so, they further supported a perception of the Summit as a feel-good exercise lacking in real consequences and missing any accountability for outcomes.

\section{From the 2020 Summit to a 'Future Australia' Community: $g 4 c 2 c$ and the $A B C$}

As politicians in Australia and elsewhere continue to envision how Government 2.0 might help to enrich and enhance democratic processes, it becomes apparent not only that the conversations and discussions that occur on various Web 2.0 channels need to be considered part of democratic culture, but also that citizens need to feel their participation in these conversations is valued as constituting active citizenship and participative democratic engagement. By not establishing an appropriate online mechanism for such participation and engagement for the longer term, the government instead risks delivering a platform which will be retrospectively perceived as reflecting 
a very 'government-centric' view, in which genuine and legitimate values that may have emerged from the summit ultimately remain tied to the rise and fall of the current government. If "to harness the best ideas across the nation" (Department of The Prime Minister and Cabinet, 2008a) was a good enough reason to stage the Australia 2020 Summit, then why should the pursuit of such ideas, crowdsourced from the Australian populace, not justify the development of a permanent 'Future Australia' community - if it can be ensured that a descent of this community into being a mere 'talkfest' is avoided?

Establishing this 'Future Australia' community, continuing the spirit of the 2020 Summit, is only worthwhile, however, if quantity and quality are addressed: if the participation of citizens and political actors within it is as impactful as it is meaningful. The appropriate model for its operations is g4c2c, rather than g2c or c2c: while c2c participation and engagement tools that are developed in a 'bottom-up' fashion may provide a better chance for functioning, self-organising user communities to emerge, they are also more easily ignored by governments not directly involved in their running; on the other hand, while such detachment is less easily possible if governments have immediate ownership of and control over the community spaces, it becomes more unlikely that constructive citizen engagement will emerge in a government-controlled and operated environment in the first place (Bruns \& Wilson, 2010).

A workable approach to developing lasting citizen participation that both carries meaning for its participants and impacts on government policy decisions is to partner both sides in a g4c2c model. Where possible, it is preferable to draw on existing communities in this process, of course - as Taylor-Smith writes,

"once we acknowledge that various people and organisations are producers, managers and instigators of democracy, we will recognise more online places where e-participation is thriving, though unlabelled. The challenges will be the best way to support these with good quality information and to channel their expertise and outputs to policy makers" (Taylor-Smith, 2008, pp. 84-85).

It is likely that public service broadcasters like the $A B C$ will come to emerge as the key institutions to undertake this connecting and channelling work. Already their traditional task has been to facilitate the public debate over the current state and future direction of the nation, and in the post-broadcast era this can be translated immediately into a challenge to engage with existing and establish new online spaces for public participation and engagement which do more than simply provide an opportunity for citizens to vent. More so than commercial media organisations or NGOs, public broadcasters occupy an important middle ground between government supervision and organisational independence: while (for the most part) free from direct editorial interference and immediate government direction, they are nonetheless strictly governed by their constituting charters and other internal guidelines which flow from it. Although rarely flawless, the activities of public broadcasters are undertaken (and scrutinised) with a great deal more transparency than those of corporate media or NGOs, and this contributes substantially to the significant public trust which they tend to enjoy.

In such a facilitatory role, the public broadcaster would be responsible for helping citizens find content that relates to their own circumstances, orientation or experiences by documenting (translating, as necessary, into a common vernacular) and making available to the public the relevant statements and proposals issued by government and public institutions. It would also be responsible for gathering and coordinating citizens' stories, their common fears and desires, and their deliberations upon and reactions to these problems and proposals, and where necessary for helping citizens to make meaningful social statements through (at times unfamiliar) online communications. And, importantly, it would also be expected to work with politicians and public servants to detail whatever formal arrangements emerge from the discussion, ensuring that increased citizen participation is not viewed by the public as an inauthentic 'act' of politics, but as a serious forum in which their inputs and opinions service a real and authentic relationship. In this manner, g4c2c initiatives would connect the diverse and often disparate views of citizens, 
mediating and connecting local experience and expertise and encouraging and moderating meaningful communication between citizens, social networks and representative institutions that do not necessarily share a common world view. In addition to the facilitation of conversation and debate, the role of 'interpretive intermediary' is also particularly well suited to public broadcasters, who have an established association with journalistic mediation and are thus able to keep debate informed by both providing balanced accounts of reality and by interpreting diverse perspectives to find the most common ground for the resolution of impasses.

A reliance on public broadcasters as facilitators of g4c2c initiatives would also be in line with Charles Leadbeater's observation that, increasingly, governments will move from directly providing services to creating the capacities and capabilities for doing so in the citizens and communities themselves, facilitating a move from one-size-fits-all provision of public sector goods and services for a largely passive population, to a model where government agencies are actively engaged with citizens and communities in such social provision (Leadbeater, 2004). Although necessarily imperfect and incomplete, the role played by the $A B C$ as host broadcaster of the Australia 2020 Summit - with substantial, day-long coverage on the ABC2 digital television channel - may be seen as an early precursor of what the future may hold in this space. A re-run of the 2020 Summit in a few years' time would (and should) also transfer responsibility for the Summit's online presence to the $A B C$, out of the hands of the government, thus enabling the $A B C$ to present an even fuller account of the Summiteers' activities in text, audio, and video, and to invite its users to connect and engage directly with developments in Canberra. This would also be combined with extensive pre and post-Summit activities, orchestrated in good part through the Summit Website.

Additionally, beyond the Summit site and its discussion fora itself, it would also be crucial to incorporate the outcomes of discussions which take place elsewhere - especially through the spaces of by now very well-established, universal social media platforms. Rather than relying on a 'build it and they will come' philosophy that attempts to force potential participants into new online environments which are both unfamiliar and potentially inferior in sophistication to mainstream social media sites - and which, most importantly, would require participants to develop a new profile from scratch rather than being able to draw on their established online presence - this distributed approach would find prospective participants where they already have a presence, tapping into already established, active communities. The value of such 'outgoing' approaches can be observed in a number of existing cases - for example during crisis events, where authorities have addressed pre-existing Twitter or Facebook communities in situ, rather than setting up new online spaces which prospective participants would have had to join first (Bruns, 2011). Further, of course, online Summit activities would also have to be complemented with additional offline events: the Summit itself would thus become only the tip of the iceberg in an effort that puts the collective intelligence of the whole nation to work, rather than remaining a relatively disconnected gathering of Australia's elite personalities only.

If citizens continue to feel excluded from agenda-setting and continue to note that nothing really arises from their contribution in 'citizen engagement' spaces, they will continue to mistrust government-driven initiatives. On the other hand, if citizens feel that they are able to participate in democratic processes, and to see tangible outcomes emerging from such engagement, they may instead develop a growing inclination to participate more deeply in future initiatives. A publiclyowned, government-supported 'Future Australia' space for citizen engagement that is not tied to party politics but recognised by politicians as a legitimate source of policy ideas could represent the broader Australian community by employing Web 2.0 applications and social media to establish, activate, and strengthen the public sphere. It could accommodate the debate and contestation that is necessary in any democratic system, yet remain committed to the constructive generation of innovative policy ideas independent of political colour or creed. Managed in this way, a g4c2c platform would ultimately serve to educate and inform politicians as well as citizens, and enhance and strengthen democratic discourse and political participation within communities.

What we propose here, then, is an emerging space for new policy initiatives that will, in turn, help shape and strengthen democratic citizenship by encouraging a culture of engagement and 
participation. The shaping of such policy would follow Coleman and Blumler's proposed civic commons in cyberspace - a democratic online space that is both:

"a recognised, accessible and trusted place or common ground," and "a space between that is neither state-dominated nor privatised, neither incorporated within existing constellations of power nor detached from them. Defined in terms of its negative relationship to power elites, an online civic commons would stand invulnerable to the claims and tactics of vested interests seeking to buy out, shut up, drown out or override the voices of the public" (2009, pp.163164):

"The creation of trusted and protected spaces facilitating cross-cutting and pluralistic flows of public communication calls for the kind of policy initiatives hitherto applied to free education, library services and public service broadcasting. In economic terms, these are externalities that can be sustained only by an institutional commitment to the public good. It is precisely such a policy that our enervated democracy now requires" (Coleman \& Blumler, 2009, p. 165).

We would encourage the trial of such a g4c2c platform, supported in a non-governmental thirdparty space. In an initial small scale offering, the trial would gauge the support surrounding g4c2c initiatives and would focus, in the first instance, on community issues that are seen as unproblematic or 'soft', rather than politically sensitive issues. As part of a phased rollout, the project should seek to build and attract a community from a relatively small group of initial participants recruited for this specific purpose. Growing the community in this way will ensure that comment and discussion remain on-topic, that participants remain civil, and that newcomers are effectively socialised into the established environment (Bruns and Bahnisch, 2009; Bruns, 2009). As the community grows and becomes more diverse and resilient, the phased introduction of more politically sensitive issues, greater dissent and oppositional voices will continue to test the resolve of both the platform and the community. During this phase, the on-site community and its discussions would also be connected more strongly with related discussions on other social media platforms.

Additional questions that would need to be addressed both prior to and during the project concern the extent to which the public are able to operate and trust the participation and consultation tools that are deployed. How, for example, would citizens new to Web 2.0 tools develop the literacies required to differentiate between authentic and inauthentic interactions that occur within the space? Here, too, the established role of public service broadcasters as educators and mediators (not least in political matters) places them exceptionally well to take up the challenge; to name just one example, the BBC digital storytelling initiative Capture Wales was also an important exercise in developing the practices of active citizenship, for example (Hartley \& McWilliam, 2009). Similarly, would casual users accept that facilitators' summaries and analyses of community discussions actually reflected the community's beliefs and preferences, or would they perceive interactions on the system as distorting or oversimplifying their views? This is a question which connects with observations about the transforming role of journalists in a changing informational environment, from one of being unchallenged reporters of information to their audiences to one of being involved moderators of user discussion and exchange about the events of the day - and public broadcasters' leadership in addressing this changing professional understanding also raises the hope that their staff may have the capacity for even-handed community facilitation. Finally, even if the g4c2c platform was trusted to accurately reflect the deliberations of its participants, would participants - and non-participants - see it as an accurate and legitimate reflection of the whole of society? And if not, would it matter, as the policy ideas generated through this approach must still undergo the conventional, representative parliamentary process? 


\section{References}

Australian Broadcasting Corporation (2009). Mark Scott Addresses Media 140 conference, 5 Nov. 2009. Retrieved January 8, 2010 from http://www.abc.net.au/corp/pubs/media/s2733848.htm

Australian Electoral Commission (2009a). Voter Turnout for Referendums and Elections 1901 - Present. Retrieved November 6, 2009, from http://www.aec.gov.au/Elections/Australian Electoral History/Voter Turnout.htm

Australian Electoral Commission (2009b). Informal Voting by Division for House of Representatives 1987 - Present (\%). Retrieved November 6, 2009, from http://www.aec.gov.au/Voting/Informal Voting/division.htm

Bruns, A. (2008a). Australian Journalists Incapable of 2020 Vision? Retrieved December 3, 2009, from http://snurb.info/node/803

Bruns, A. (2008b). Blogs, Wikipedia, Second Life, and Beyond : From Production to Produsage, Digital Formations, 45. New York: Peter Lang.

Bruns, A. \& Bahnisch, M. (2009). Social Media Volume 1 - State of the Art, Smart Services CRC, Sydney, 2009. Retrieved January 8, 2010 from http://snurb.info/files/Social\%20Media\%20-\%20State\%20of\%20the\%20Art\%20\%20March\%202009.pdf

Bruns, A. (2009). Social Media Volume 2 - User Engagement Strategies, Smart Services CRC, Sydney, 2009. Retrieved January $\quad 8,2010$ from http://snurb.info/files/Social\%20Media\%20Report\%20Volume\%202\%20\%20User\%20Engagement\%20 Strategies.pdf

Bruns, A. (2011). The Queensland Floods on Twitter: A Brief First Look. Mapping Online Publics, 17 Jan. 2011. Retrieved 11 Feb. 2011 from http://www.mappingonlinepublics.net/2011/01/17/the-queensland-floods-on-twitter-a-brief-first$\underline{\text { look/ }}$

Bruns, A \& Wilson, J. (2010). Citizen Consultation from Above and Below: The Australian Perspective. In C. Reddick (Ed.), Politics, Democracy and E-Government: Participation and Service Delivery (pp.332-346). Hershey, PA: IGI Global.

Coleman, S. (2005). The Lonely Citizen: Indirect Representation in an Age of Networks, Political Communication, 22(2), 197-214.

Coleman, S. \& Blumler, J.G. (2009). The Internet and Democratic Citizenship: Theory, Practice and Policy. Cambridge: Cambridge University Press.

Council of Europe's Ad Hoc Committee on e-Democracy (2008). Indicative Guide No 1: Generic Tools and Policies for an Electronic Democracy, CAHDE 4th Plenary Meeting, Strasbourg, 13-14 Nov. 2008. Retrieved November 16, 2009, from http://www.coe.int/t/e/integrated projects/democracy/02 activities/002 e\%2Ddemocracy/CAHDE\%20 indicative\%20guide\%20no\%201\%20Eonly 23Feb09 PDF.pdf

Council of Europe's Ad Hoc Committee on e-Democracy (2009). Recommendation CM/Rec(2009)1 of the Committee of Ministers to Member States on Electronic Democracy (e-Democracy), CAHDE 4th Plenary Meeting, Strasbourg, 1314 Nov. 2008. Retrieved November 16, 2009, from http://www.coe.int/t/e/integrated projects/democracy/ 02 activities/002 e\%2Ddemocracy/Recommendation\%20CM Rec 2009 1E FINAL PDF.pdf

Crabb, A (2008). Live Summit Blog, Sydney Morning Herald, 19 Apr. 2008. Retrieved December 3, 2009, from http://blogs.smh.com.au/newsblog/ archives/annabel crabb/017957.html

Department of The Prime Minister and Cabinet (2008a). Australia 2020: About the Summit. Retrieved November 6, 2009 from http://www.australia2020.gov.au/about/index.cfm

Department of the Prime Minister and Cabinet (2008b). Australia 2020 Summit - Final Report, May 2008. Retrieved January 7, $2010 \mathrm{from} \mathrm{http://www.australia2020.gov.au/docs/final} \mathrm{report/2020} \mathrm{summit} \mathrm{report} \mathrm{full.pdf}$

Flew, T., \& Cunningham, S., \& Bruns, A., \& Wilson, J. (2008). Social Innovation, User-Created Content and the Future of the $A B C$ and SBS as Public Service Media. Submission to the ABC and SBS Review, Australian Federal Department of Broadband, Communications, and the Digital Economy, Brisbane, 12 Dec. 2008. Retrieved January 8, 2010 from http://snurb.info/files/ABC SBS\%20Inquiry Flew\%20et\%20al.pdf

Government 2.0 Taskforce, Department of Finance and Deregulation (2009). Engage: Getting on with Government 2.0., Dec. 2009. Retrieved January 7, 2010 from http://www.finance.gov.au/publications/gov20taskforcereport/doc/ Government20TaskforceReport.pdf

Griffiths, M (2009). eDemocracy Design: Citizen Consultation on Contentious Issues. In A. Prosser \& P. Parycek (Eds.), Proceedings of EDEM 2009 - Conference on Electronic Democracy (pp. 51-59). Vienna, 7-8 Sep. 2009.

Harvey, L. (2009). 2020 Summit: What Might Have Been. Government 2.0 Task Force, 2 Oct. 2009. Retrieved November 6 , 2009 from http://gov2.net.au/blog/2009/10/02/2020-summit-what-might-have-been/

Hartley, J., \& McWilliam, K. (Eds.) (2009). Story Circle: Digital Storytelling around the World. Malden, MA: WaldenBlackwell.

Leadbeater, C. (2008). We-Think: Mass Innovation, not Mass Production. London: Profile Books. 
Leadbeater, C. (2004). Personalisation through Participation: A New Script for Public Services. London: Demos.

Taylor-Smith, E. (2008). e-Democracy Relationships and Responsibilities. In Council of Europe Forum for the Future of Democracy, e-Democracy: Who Dares? Forum for the Future of Democracy (pp. 79-86.) Madrid, 15-17 Oct. 2008.

\section{About the Author}

\section{Axel Bruns}

Dr Axel Bruns is an Associate Professor in the Creative Industries Faculty at Queensland University of Technology in Brisbane, Australia. He is a Chief Investigator in the ARC Centre of Excellence for Creative Industries and Innovation (CCi), and has been a Senior Researcher in the Smart Services Cooperative Research Centre. Bruns is the author of Blogs, Wikipedia, Second Life and Beyond: From Production to Produsage (2008) and Gatewatching: Collaborative Online News Production (2005), and the editor of Uses of Blogs with Joanne Jacobs (2006; all released by Peter Lang, New York). Bruns has coined the term produsage to better describe the current paradigm shift towards user-led forms of collaborative content creation which are proving to have an increasing impact on media, economy, law, social practices, and democracy itself. Produsage provides a new approach to conceptualising these phenomena by avoiding the traditional assumptions associated with industrial-age production models (see http://produsage.org/). Bruns's Website is at http://snurb.info/.

\section{Adam Swift}

Dr Adam Swift is a research associate in the Creative Industries Faculty at Queensland University of Technology in Brisbane, Australia, and is currently part of a Smart Services Cooperative Research Centre team exploring social trends in online news and information services. Swift has published on a range of topics associated with user engagement with New Media Technologies. 